\title{
EL EMBLEMA MUSICAL DE LA VANITAS EN EL TRATADO INSTRUMENTAL DE LUIS VENEGAS DE HENESTROSA (1557)
}

\author{
THE MUSICAL EMBLEM OF VANITAS IN LUIS VENEGAS \\ DE HENESTROSA'S INSTRUMENTAL TREATISE (1557)
}

\author{
Montiel Seguí \\ Universitat de València \\ http://orcid.org/0000-0002-6263-272X
}

ABSTRACT: In 1557 the Libro de cifra nueva para tecla, arpa y vihuela, written by the priest Luis Venegas de Henestrosa, was published in Alcalá de Henares by the press of Juan de Brocar. Dedicated to the bishop of Jaén, Diego Tavera, and paying homage to the late Cardinal Juan Pardo de Tavera, the treatise included in its initial pages an emblem with a message about the transience of life or vanitas. The rhetorical-musical iconographic program becomes a mysterious image, implicitly carrying the three faculties of time: the past, the present and the future. The emblematic corpus is configured by merging the different arts with a musical enigma that sings Coplas por la muerte de su padre, Recuerde el alma dormida, by Don Jorge Manrique, with images ready to be interpreted and with messages veiled in psalms and biblical references. Underlying it all is a moralizing intent. This is the first musical emblem of Spain with notation spellings that have been conserved, remarkable if we consider Andrea Alciato's publication (1531) as the starting point of the so-called emblematic genre.

KEYWORDS: Musical Emblem; Luis Venegas de Henestrosa; Vanitas; Prudence.

RESUMEN: En 1557 se publicaba en Alcalá de Henares, en la imprenta de Juan de Brocar, el Libro de cifra nueva para tecla, arpa y vihuela escrito por el profeso Luis Venegas de Henestrosa. Dedicado al obispo de Jaén Diego Tavera y rindiendo pleitesía al fallecido cardenal Juan Pardo de Tavera, el tratado incluía en sus iniciales páginas un emblema con un mensaje sobre la fugacidad de la vida o vanitas. El programa iconográfico retórico-musical se torna en estampa misteriosa llevando implícito las tres facultades del tiempo: el pasado, el presente y el porvenir. El corpus emblemático se configura fusionando las distintas artes con un enigma musical que entona las Coplas por la muerte de su padre, Recuerde el alma dormida, de don Jorge Manrique, con imágenes dispuestas a ser interpretadas y con mensajes velados en salmos y referencias bíblicas. Bajo todo un sentido moralizante nos encontramos ante el primer emblema musical de España con grafías de notación que conservamos, considerando la publicación de Andrea Alciato (1531) como punto de partida del denominado género emblemático.

PALABRAS CLAVES: Emblemática musical; Luis Venegas de Henestrosa; Vanitas; Prudencia. 


\section{INTRODUCCIÓN}

La clave de la lectura emblemática reside en la combinación, en el mismo programa iconográfico, del artificio retórico de varias artes en estado dialéctico puestas al servicio de un mismo propósito o significado. La era del Quinientos, en la que la idea de futuro era volver al pasado, había tomado prestada de la cultura griega aquella interdisciplinariedad natural que unía las cosas entre sí ${ }^{1} \sin$ imponer tampoco barrera entre ciencia y arte, pues las mismas fuerzas de la naturaleza eran el eje de maestrías como la química, la medicina, la astrología, las matemáticas, entre otras. Mientras, las propias artes serían benefactoras del valor de la ciencia para su desarrollo. Inquietudes intelectuales y creativas compartían el escenario de un mundo que se estaba forjando entre el arte más persuasivo y la ciencia moderna.

En 1531 veía la luz en Augsburgo uno de los libros más influyentes en la cultura occidental europea. El Emblematum liber, escrito por el jurisconsulto milanés Andrea Alciato, exponía una serie de epigramas moralizantes, ilustrados por decisión del editor. La difusión del tratado, tanto por su didáctica como por sus atractivas estampas, fuentes de inspiración para las artes, alcanzó un gran número de ediciones gracias a la revolución comunicativa que supuso la imprenta. Del conjunto de emblemas que se representan en la obra de Alciato, ocho tratan sobre música o se apoyan en ella para comunicar un mensaje mostrando instrumentos musicales, por lo general, característicos de la época. Estableciéndose el arte del sonido como recurrente elemento constitutivo de la Emblemática, la música expandió sus dominios y el lenguaje musical se integró en el discurso visual configurándose dos tipologías: emblemática con imágenes musicales y emblemática con partituras. Por este motivo, tras la observación documental de las fuentes, vemos necesario proponer una taxonomía que represente las dos vertientes emblemáticas, a la vez que, tras esta ordenación, podamos conducir la forma, con sus partes constitutivas, hacia el significado de la obra centro de estudio: el emblema musical de la vanitas en los folios iniciales del tratado instrumental de Luis Venegas de Henestrosa, titulado Libro de cifra nueva para tecla, harpa y vihuela, publicado en Alcalá de Henares en 1557, en la imprenta de Juan de Brocar. Esta xilografía ha pasado desapercibida en los estudios especializados sin que se haya considerado desde la disciplina de la Historia del Arte, pudiéndose tratar del primer emblema musical español con grafía de notación que conservamos, tomando como punto cronológico de referencia la inauguración del género literario de la Emblemática con Alciato. Por sus características, responde a ser fiel espejo de la tradición cultural convencionalizada del Renacimiento en España. La fusión de distintas artes con sus artificios retóricos: música, literatura -los versos de Jorge Manrique, salmos, citas bíblicas-, pictura, ciencia, junto a un elaborado mensaje hermético sobre el misterio de la fugacidad de vida, lo configuran como un excelente exponente de este género.

1. «Como ha puntualizado Foucault en Les mots et les choses (cap. I, nota 10), el siglo XVI fue la edad de las correspondencias, ya que el hombre de esta época basó su conocimiento en la asociación de una forma de lenguaje con otra para alcanzar la unidad de palabras y cosas, combinando para ello las palabras con las imágenes» (Sebastián, 1995: 11). 


\section{BREVE APROXIMACIÓN A LA REPRESENTACIÓN DE LA VANIDAD EN LA HISTORIA DEL ARTE}

El «espíritu del Eclesiastés» (Rodríguez de la Flor, 2007: 339) dejó mucha producción en la Historia del Arte, reflejando un modo de ver la vida alrededor del sentido de esta con la muerte o con la fugacidad del tiempo.

La dualidad de la música: ser sonada o ser silencio se asemejó análogamente a la vida y al sueño eterno. Placer sensorial que debía deleitar en su justa medida, el arte del sonido se exponía en los programas retórico-visuales del género de la vanitas para proporcionar didácticamente un mensaje junto a otros atributos alusivos a las banalidades mundanas y a la brevedad de las horas: las joyas, las monedas, el reloj, la máscara, las flores, la tiara papal, los libros, el globo terráqueo, el cetro, el espejo, el cráneo y el gesto melancólico o de adormecimiento, entre otros.

La relación entre música y óbito asoma temprana en las escenas de las Danzas de la muerte inundando ciertos discursos visuales medievales. Los esqueletos son tañedores que acompañan al difunto danzando y tocando instrumentos musicales: tambores, flautas y trompetas, por lo general. ${ }^{2}$ Aunque no conservamos testimonios musicales de las danzas, como decíamos, preservamos una producción icónica y organográfica rica en miniaturas en tratados, Libros de Horas -oficio de difuntos-, en soporte mural, en camposantos, etc. "Cuando el fenómeno florece con mayor esplendor ya en el siglo XV, los instrumentos estarán siempre presentes en la iconografía y no de manera parcial ni anecdótica" (Infantes, 1997: 133). Las representaciones dramático-litúrgicas del Medioevo eran comunes en la sociedad, por lo que las Danzas de la muerte pudieron ser tendencia nacida de este contexto social, teniendo en cuenta, como apunta Víctor Infantes (1997), el tema de las pestes y el imaginario surgido por el miedo a perecer, aceptando la muerte -tanto para ricos como para pobres- como lo más certero para el ser humano.

La Revolución científica trajo consigo los nuevos estudios de anatomía y fisiología del cuerpo humano. La publicación impresa en volúmenes científicos de láminas grabadas ${ }^{3}-$ con huesos, cráneos, esqueletos, etc.-, empleadas por los artistas como modelos para elaborar sus obras, contribuyó a la difusión de los tratados sobre medicina, estructura y forma humana. Las estampas que ejemplificaban los avances en los estudios del hombre a partir la Edad Moderna -basados principalmente en la observación y en la experimentación-, convertían el nuevo resurgir científico en un campo ideal para presentar también a la vanitas. En la denominada «anatomía moralizada» (López Terrada y Jerez Moliner, 1994: 10) se correspondían la ciencia y el significado de la vanidad ensambladas como un mismo arte. Los estudios de López Terrada y Jerez Moliner (1994) interpretan el Atlas anatómico de Crisóstomo

\footnotetext{
2. "Dentro de estos instrumentos apropiados para la danza, el siglo XV distinguía dos tipos: hauts instruments y bas instruments. Los primeros eran los indicados para ceremonias al aire libre y entre ellos se cuentan los pertenecientes a la familia de viento, muy populares a finales del siglo XIV, y, especialmente las distintas variedades de percusión. Los bas instruments eran los más indicados para audiciones y danzas interiores, especialmente los instrumentos de cuerda: arpa, viola, laúdes y cítaras [...] los bas instruments sirven para indicar un ambiente cortesano y acompañan a las figuras más relevantes: el papa, el rey, etc., siendo más alegóricos que reales» (Infantes, 1997: 135).

3. La imprenta, hasta entrada la modernidad, se consideró una actividad sobresaliente: «[...] ojear páginas impresas era una rutina familiar en los círculos eruditos del siglo XVII [...] Kepler, que se pasaba horas en los talleres de imprenta, supervisando de cerca la impresión de sus obras científicas, estaba informando sobre la tecnología de impresión [...]» (Eisenstein, 2010: 17).
} 
Martínez como ejemplo de vanitas dotado de una gran exquisitez de detalles óseos. Al respecto este estudio dice:

Este tipo de estampas anatómicas inspiraron expresamente a las pinturas de vanitas. Según Lambotte los tratados de anatomía fueron las primeras obras en incluir grabados sobre los temas de la muerte inevitable y de la fragilidad humana y sus dibujos se inspiraron ampliamente en la imagen medieval de la Danza Macabra. Estas láminas son, pues, una buena muestra de la mentalidad barroca, escindida entre el nacimiento de una idea moderna y racional de la ciencia y un mundo donde lo patético es un elemento cotidiano (López Terrada y Jerez Moliner, 1994: 7).

La dualidad ciencia-arte quedaba latente en distintos grabados de la época, por ejemplo en De humani corporis fabrica, de 1543, de Andrea Vesalio, encontramos la imago de un esqueleto contemplando, con actitud melancólica, un cráneo reposado sobre un pedestal a la clásica, en alusión al paso del tiempo. En España la misma estampa fue recogida por Juan Valverde -médico que viaja a Italia en 1552 para aprender los nuevos avances en anatomía humana establecidos por el bruselense- en su obra de 1556: Historia de la composición del cuerpo humano. ${ }^{4}$

Los libros de emblemas serían escenario del halo enigmático y aciago de la vanitas. En los españoles es habitual encontrar a la vanidad. Por ejemplo, Juan de Horozco en el emblema XXXIV del libro II de los Emblemas morales (1591) muestra a Damocles seducido por el sonido de un cordófono -similar a un laúd-y el de un pandero, hasta que concurre sobre su cabeza la espada como significación de lo efímero de su vida y la inutilidad de los placeres terrenales. Juan de Borja (1680: I, 198-199), bajo el mote «Hominem te ese cogita», "recuerda al hombre que su presente, su ahora, es ser una calavera como la que conforma la pictura de la empresa y que, en definitiva, es polvo y ceniza» (Vives-Ferrándiz, 2011: 89).

En este modo particular de ver la vida aparecía en escena la Prudencia «como la disposición adecuada para descubrir el engaño del mundo. La práctica de la prudencia consiste en mirar por dentro o en adoptar el rostro bifronte de Jano que mira hacia las diversas dimensiones del tiempo (el pasado y el futuro), [...] Es una virtud que juega con tres dimensiones del tiempo" (Vives-Ferrándiz, 2011 : 17). La mirada hacia varios lugares indica, además, la virtud de la Prudencia gobernado las tres dimensiones del tiempo (Vives-Ferrándiz, 2011). Las tres modalidades del tiempo son definidas por Cicerón de la siguiente manera:

El conocimiento de lo que está bien y lo que está mal y lo que no es ni una cosa ni la otra. Sus partes son la memoria, la inteligencia y la previsión. La memoria es la facultad que permite al espíritu recordar los acontecimientos pasados; la inteligencia, lo que hace comprender los acontecimientos presentes; y la previsión, lo que permite adivinar las cosas antes de que sucedan (Cic., Inv. 2, 53-160).

De igual manera que Cicerón, Erwin Panofsky subordina la virtud a estas tres modalidades, las «tres facultades que son la memoria, la inteligencia y la previsión» (Panofsky, 1987: $173)$.

\footnotetext{
4. Escribe en el inicio de su obra: "Aunque a algunos amigos míos parecía, que yo deviesse hazer nuevas figuras, sin servirme de las de Vesalio, no lo he querido hazer por, evitar la confusión que dello se pudiera seguir, no se conociendo tan fácilmente enlo que convengo o desconvengo conel, y porque sus figuras están también hechas que me pareciera invidia o maliñidad no querer aprovecharme dellas [...]" (Valverde, 1556: iii).

5. Para profundizar en el estudio de las Empresas Morales de Juan de Borja véase: García Mahíques, R. [1998]. Empresas Morales de Juan de Borja: imagen y palabra para una iconología. Valencia: Ajuntament de València.
} 
Según los estudios de María Montesinos los primeros ejemplos visuales de la bifrontalidad de la Prudencia pertenecen al ámbito italiano (Montesinos, 2017: 508), en concreto a los frescos de Giotto en la Capilla Scrovegni (Padua). En estas pinturas se añaden nuevos atributos a la imagen: un libro y un espejo ${ }^{6}$ que ayuda a la Prudencia a conocerse a sí misma para emplearse en las buenas acciones. Es en la Italia del siglo XIV cuando se referencia el tiempo en sus tres estados en diferentes programas visuales con la imagen trifaz de la Prudencia, como, por ejemplo, en el Arca de San Agustín en Pavía (San Pietro in Ciel d'Oro) o en la tumba de san Pedro Mártir (Capilla Portinari, Basílica de San Eustorgio, Milán) (Montesinos, 2017).

\section{HACIA UNA PROPUESTA DE CLASIFICACIÓN PARA LA EMBLEMÁTICA QUE INCORPORA EMBLEMAS CON ELEMENTOS MUSICALES}

Aunque por emblemática musical entendemos por lo general toda aquella producción de emblemas en relación con la música, debemos diferenciar dos tipologías que caracterizan a los emblemas que incorporan elementos musicales: la emblemática que trata sobre música y la emblemática musical propiamente dicha.

La emblemática que trata sobre música es aquella en la que, sin variar el triple constructo emblemático: imagen-mote-epigrama, la música es un elemento del discurso representado a través de un componente icónico-musical, predominantemente organográfico. Juan de Borja (1680: I, 182-183) muestra en su empresa «Interna suavissima» un laúd como figura retórica de la templanza y de la armonía interior.

La emblemática musical, en cambio, es aquella cuya estructura emblemática se constituye de modo cuatripartito: pictura-lemma-subscriptio-figuras de notación. La música, junto a las otras artes, se integrará en el discurso verbo-visual mediante la retórica añadiendo así el componente musical a dicho discurso. Este tipo emblemático puede incorporar también el componente icónico-musical, pero lo caracterizan las grafías musicales que pueden ser transcritas a notación actual. El magnífico emblema «Praestolari cum silentio» de Juan de Borja (1680: II, 292-293) es un ejemplo de emblemática musical puesto que en él aparecen, junto a la pictura y la subscriptio, grafías de notación dispuestas a ser analizadas trazando un puente en la comunicación con las cualidades expresivas y las significantes.

\section{EL EMBLEMA MUSICAL DE LA VANITAS DE VENEGAS DE HENESTROSA}

En 1557 veía la luz un tratado instrumental en Alcalá de Henares, en la imprenta de Juan de Brocar, ${ }^{7}$ bajo la autoría del clérigo Luis Venegas de Henestrosa. Dedicado al obispo de Jaén, Diego Tavera, Venegas rendía pleitesía al fallecido cardenal Juan Pardo de Tavera.

6. «Si el presente del ser humano es equiparado a una calavera para denotar su carácter mortal y perecedero, el espejo es el objeto más adecuado para reflejar en su superficie esa condición» (Vives-Ferrándiz, 2011: 102).

7. Hijo de Arnao Guillén de Brocar, el impresor patrocinado y dirigido por el Cardenal Jiménez de Cisneros y llevado por este a Alcalá, Juan de Brocar comenzó a «imprimir alrededor de 1538 y trabajó hasta su muerte en 1552 , fue un prolífico impresor que produjo una gran cantidad muy grande de libros en esta villa» (Lyell, 2012: 312 ).

IMAGO, NÚM. 13, 2021, 7-23 
Conservados dos ejemplares en la Biblioteca Nacional de España, ${ }^{8}$ procedentes del legado Barbieri, el opúsculo titulado Libro de cifra nueva para tecla, arpa y vihuela empleaba en la enseñanza musical un tipo de notación musical denominada "cifra». ${ }^{10}$ Sencilla, práctica y muy visual no requería dominar la compleja teoría musical, por lo que el rico repertorio polifónico vocal, reservado hasta entonces, pasaba a ser adaptado para tañedores cortesanos o de cualquier otro estamento social que quisiesen interpretar la música.

Luis Venegas de Henestrosa (1510-1570), nacido en Écija, Sevilla, fue un tratadista musical español, clérigo, del que poca biografía conocemos. Existe una edición facsímil editada, en 1984, por Higinio Anglés con la transcripción del texto del tratado de Venegas donde el sevillano da escasos datos sobre sí mismo. Los estudios de Jaume Moll (1951), además de los de Louis Jambou y François Reynaud (1984), aportaron luz a su biografía y dieron a conocer su testamento, revelando datos muy valiosos sobre este personaje: «era en 1543 sacerdote y cura de la villa de Hontoba (provincia de Guadalajara)" (Jambou y Reynaud, 1984: 419-420). Gracias al Chronico de el Cardenal don Juan Tavera sabemos que fue administrador del Hospital Tavera, de san Juan o de las afueras en Toledo:

El nono Luys Venegas de Henestrosa de la Camara de el Cardenal, natural de Ecija, desde primero de Agosto, de el año se setenta, hasta los postreros de Noviembre de el dicho año, que dexó el oficio, por no hallarse bien de salud. Murio cura de Taracena, cerca de Guadalajara (Salazar y Mendoza, 1603: 304).

La relación con Juan Pardo de Tavera queda constatada en el Libro de cifra nueva, al rendirle pleitesía al que fuere arzobispo de Toledo:

[...] mi señor, y tio de vuestra señoria reverendissima, y las mercedes que me hizo, admitiéndome entre tantos cavalleros hijos de señores, y de sangre real, como tenia en su cámara, y desseando que se offreciesse algo en que se conociesse lo mucho que desseo servir a sus cosas, me parecio ofrecer este pequeño presente a vuestra señoria, pues aquel sancto varon se fue al cielo tan temprano para los suyos. Quisiera descubrir como testigo de vista algunas de la gran armonia de virtudes que el cardenal mi señor trabajava de encubrir. Mas por evitar sospecha de lisonja, y por que mi baxo ingenio no las borre, como incapaz para poderlas comprehender, sera lo mas seguro pasarlas en silencio (Venegas de Henestrosa, 1557: fol. $i \mathrm{v}$ ).

La estampa xilográfica de los folios iniciales [fig. 1] pertenece al género de la Emblemática, característica en el siglo XVI, presentando un corpus cuatripartito que consta de:

- Motto: «Certum/In incerto». Junto a la cita bíblica de san Juan (Jn 12,25): «Qui amat anumat suam, perdet eam»; la del salmo (Sal 49,22): "Intelligite, haec, qui obliviscimini Deum. Ne quando rapiat et non sit qui eripiat»; e "Infern"».

- El epigrama queda constituido con los versos de las Coplas por la muerte de su padre, Recuerde el alma dormida, de don Jorge Manrique:

8. Según reza en la descripción de la Biblioteca Nacional de España: Descripción física: [2]. 76 h.; Fol. / Signaturas: $\mathrm{R} / 6497, \mathrm{R} / 598$.

9. Libro de cifra nueua para tecla, harpa, y vihuela: en el qual se enseña breuemente cantar canto llano, y canto de organo, y algunos auisos para contrapunto / compuesto por Luys Venegas de Henestrosa, dirigido al illustrissimo señor don Diego Tauera, obispo de Iaen.

10. "Así como los vihuelistas tienen su cifra o escritura propia, este libro inaugura una particular para los instrumentos de tecla, no usada hasta entonces, por donde Venegas la llama nueva, que será, con ligeras variantes, la misma que utilizará Hernando de Cabezón en las obras de su padre Antonio» (Rubio, 2006: 237). 
Recuerde el alma dormida.

Avive el seso y despierte,

Contemplando.

Como se pasa la vida.

Como se viene la muerte,

Tan callando (vv. 1-6).

- La imago se configura con el esqueleto, el pergamino donde se halla la notación musical, el "mundo en T» sobre el que descansan edificaciones sagradas a doble agua, un jinete a la caza alzando su arma contra una bestia y un personaje que contempla el globo y sostiene la serpiente.

- Las figuras de notación mensural blanca se corresponden con el lenguaje musical que entona los versos de Manrique, escritos dentro del pergamino que sostiene el esqueleto.

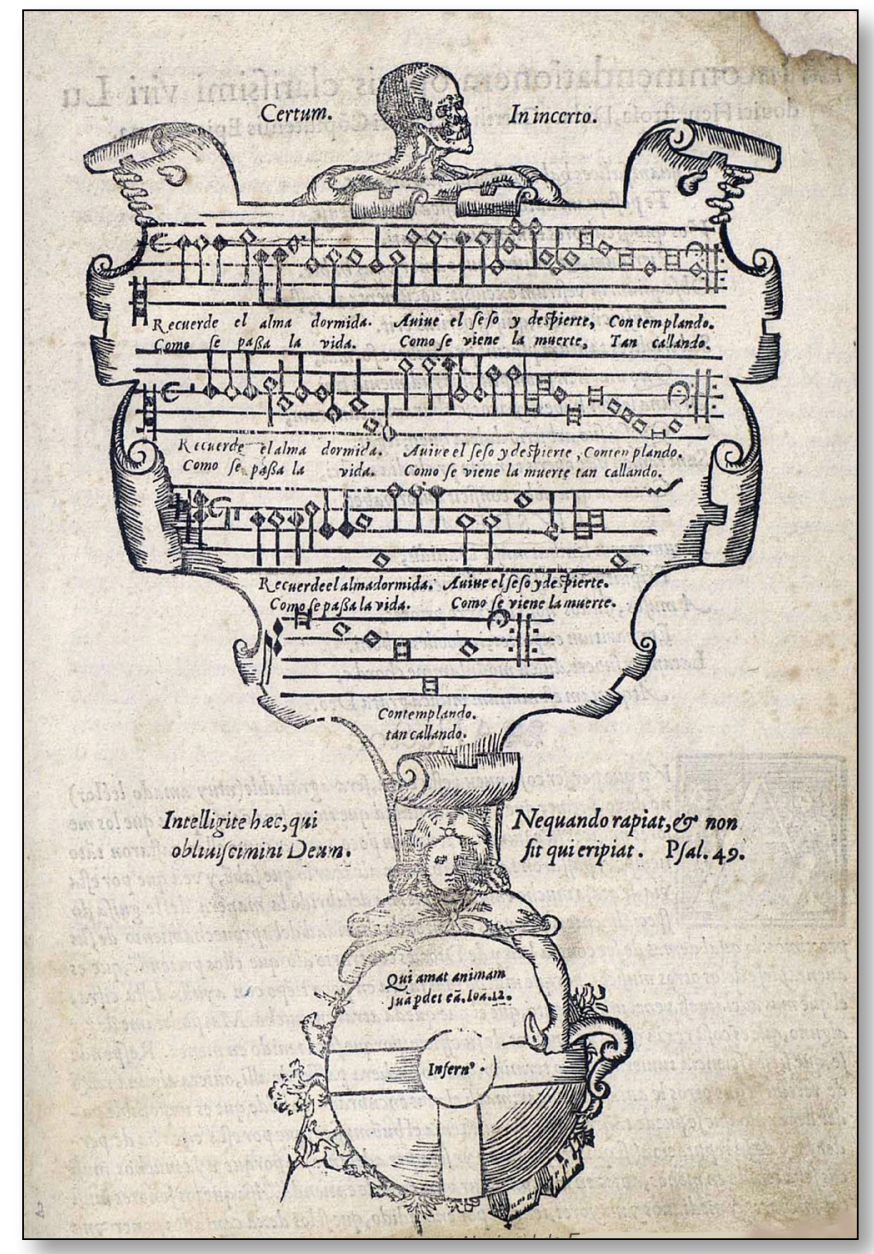

Fig. 1. Emblema musical de la vanitas. Libro de cifra nueva, Luis Venegas de Henestrosa, 1557, Alcalá de Henares. Biblioteca Nacional de España, fol. ii r. 
El emblema musical de Venegas lleva implícito el mensaje de la vanitas o de la fugacidad de la vida. El esqueleto que preside el programa iconográfico cumple la función retórica de las anatomías moralizadas, estampadas en volúmenes científicos, en cuanto a la certeza de la muerte. Mediante la fusión de las artes, el programa emblemático-retórico musical se torna en estampa hermética guardando las tres facultades del tiempo: el pasado, el presente y el porvenir, a saber, memoria, inteligencia y previsión. El binomio tiempo-vida se encripta en la arqueología del discurso visual retenido en una imagen de misterio, ${ }^{11}$ llevando contenido el paso del tiempo. Por tanto, encontraremos en el emblema musical las tres temporalidades representadas.

La calavera torna su rostro hacia el lado que reza una parte del mote «In incerto»: la incertidumbre de cuándo vendrá la muerte, por lo que es importante la previsión en la vida, la consciencia de la muerte, el desengaño para despojar las cosas terrenales de las apariencias que les son concebidas, buscando la verdadera esencia del alma, consecución que solo puede llevar a cabo el hombre a través de la iluminación divina. Mientras, en su nuca el mote reza "Certum», a saber, el pasado evocando la memoria de la muerte, recordando que estamos dormidos, clave del desengaño para la salvación del alma humana. «El recordar, el despertar, se efectúa con los ojos en la nuca de la Memoria o con la cara vuelta hacia el pasado de la Prudencia [...]» (Vives-Ferrándiz, 2011: 336).

El esqueleto sustenta con sendas manos los extremos del pergamino, de manera que sus brazos se extienden y su cuerpo queda escondido tras la vitela. Esta porta el mensaje de la vanidad en las Coplas de Manrique, Recuerde el alma ..., representando el pasado, y en la música, con gran probabilidad, compuesta por Venegas de Henestrosa, ${ }^{12}$ aunada por la retórica junto a las artes compañeras.

La torsión del cuello de la calavera no solo hace apuntar su mirada ${ }^{13}$ sobre el lema volviendo la nuca al pasado, el «Certum», sino que su oído -sentido más noble junto a la vista- se dirige hacia la música sonada. En palabras del jesuita Florencio de Medina, los cinco sentidos: "son puertas por donde se flanquea el Alma, en esta cárzel del cuerpo" (citado en Sebastián, 1995: 123). El esqueleto nos invita a la percepción auditiva y al conocimiento del lenguaje oral de los versos emisarios de Manrique. La música reveladora se almacena en la memoria que, antiguamente, se creía residente en el corazón humano. El gesto de la calavera, cualidad expresiva, nos traslada al significado: la escucha del esqueleto sigue el tempus y el ritmo de la música con los versos del poeta, como anuncio moral que reposa en la memoria del pasado. Oír el avance del tiempo musical es escuchar pasar las horas caducas de la vida, como si fuese reloj mecánico, atributo de la vanitas. Pero es un recado revelador y efectivo que sirve de guía al creyente. La música se torna despertador, es música vocal, la reservada para el ambiente sacro que venera el buen cristiano.

El salmo $(49,22)$, escrito a la altura de la cabeza del personaje que contempla el mundo y sostiene una serpiente con su mano izquierda, dice así: «Intelligite, haec, qui obliviscimini Deum. Ne quando rapiat et non sit qui eripiat». Este lema nos da un mensaje de advertencia: la muerte puede arrebatarnos la vida en cualquier momento, por eso Dios, como guía, debe estar presente durante el transcurso de esta. La figura a la que flanquea el mote [fig. 2a] contempla desde arriba el teatrum mundi y se corresponde con la alegoría de la Inteligencia

11. García Mahíques se refiere a las «imágenes de misterio» en el prólogo de Vanitas. Retórica visual de la mirada (Vives-Ferrándiz, 2011: 16) en relación al carácter emblemático que pudiese tener una imagen.

12. Miguel Querol (1981) considera que la música no es original de Venegas.

13. En este punto hay que recordar el estudio de Vives-Ferrándiz (2011): Vanitas. Retórica visual de la mirada -citado en la bibliografía adjunta en este trabajo. 
que años después ejemplificará Cesare Ripa (1593) personificada con una esfera y una serpiente [fig. 3], por lo que la alegoría de Venegas se sitúa como precedente de la de Ripa:
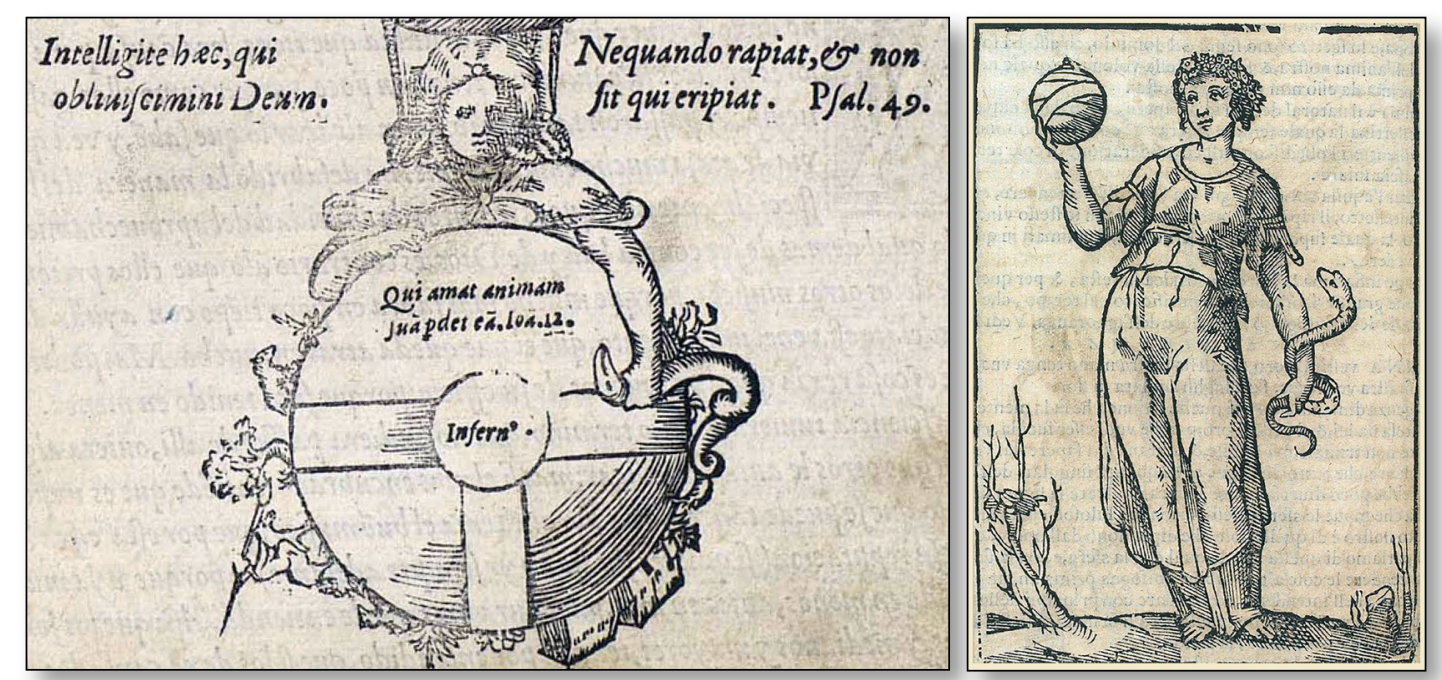

Fig. 2. Inteligencia (a), mundo en T (b), jinete (c); sentencia evangélica: «Qui Fig. 3. La Inteligencia. Iconología, Ceamat animam suam..." (d) e "Infern"» (e). Libro de cifra nueva, Luis Venegas de sare Ripa, 1603, Roma. Bibliothèque Henestrosa, 1557, Alcalá de Henares. Biblioteca Nacional de España, fol. ii r. Nationale de France, fol. 240.

Mujer vestida de oro que sostiene una esfera con la diestra y con la siniestra una sierpe [...] mediante la esfera y la sierpe, significa y enseña que, para alcanzar la comprensión de las cosas más altas y sublimes, es preciso primero arrastrarse por la tierra, como lo hacen las serpientes, obrando en nuestro entendimiento a partir de los principios de las cosas terrenas, aunque sean menos perfectas que las obras del Cielo. Por ello se ha de poner en la siniestra la sierpe, y en la diestra en cambio, que es más noble, la esfera que dijimos (Ripa, 2007: 533).

Ripa debió basarse en un ciclo tradicional medieval, ${ }^{14}$ al igual que el autor del emblema aquí estudiado, para representar a la Inteligencia (el presente). La boeciana Consolación de la Filosofía, fuente literaria muy empleada en la tradición medieval, describe a la Inteligencia asemejándola a la del emblema de Venegas: «La inteligencia contempla las cosas desde mayor altura; y pasando de la esfera de lo universal, intuye las formas simples en sí mismas, penetrándolas con su luz» (Boecio, 2006: 216). El orbe representado es un «mundo en T» [fig. 2b] de tradición medieval, todavía dividido en tres continentes: Asia, África y Europa y con los dos mares: Mediterráneo e Índico. Sobre el globo terráqueo, la silueta de un hombre a caballo direcciona una lanza hacia un animal en medio de un paisaje arbolado [fig. 2c]. Recuerda este al emblema XIV de Andrea Alciato (1531) titulado: "Consilio et virtute Chimaeram superari, id est, fortiores et deceptores», donde el jinete Belerofonte da caza a la bestia ${ }^{15}$ Quimera [fig. 4].

14. Adita Allo Manero prologa: «Mandowsky señala las analogías y diferencias que se pueden plantear entre Iconología y los grandes compendios del saber de la Edad Media: las summas medievales, dado el carácter enciclopédico que las caracteriza» (Ripa, 2007, 1: 12).

15. «El contenido alegórico que puede tener un bestiario está demostrado por las historias de los Padres del desierto, de los eremitas o cenobitas [...]. Los animales que aparecen en estas narraciones aretológicas tienen diverso carácter, pero en

IMAGO, NÚM. 13, 2021, 7-23 


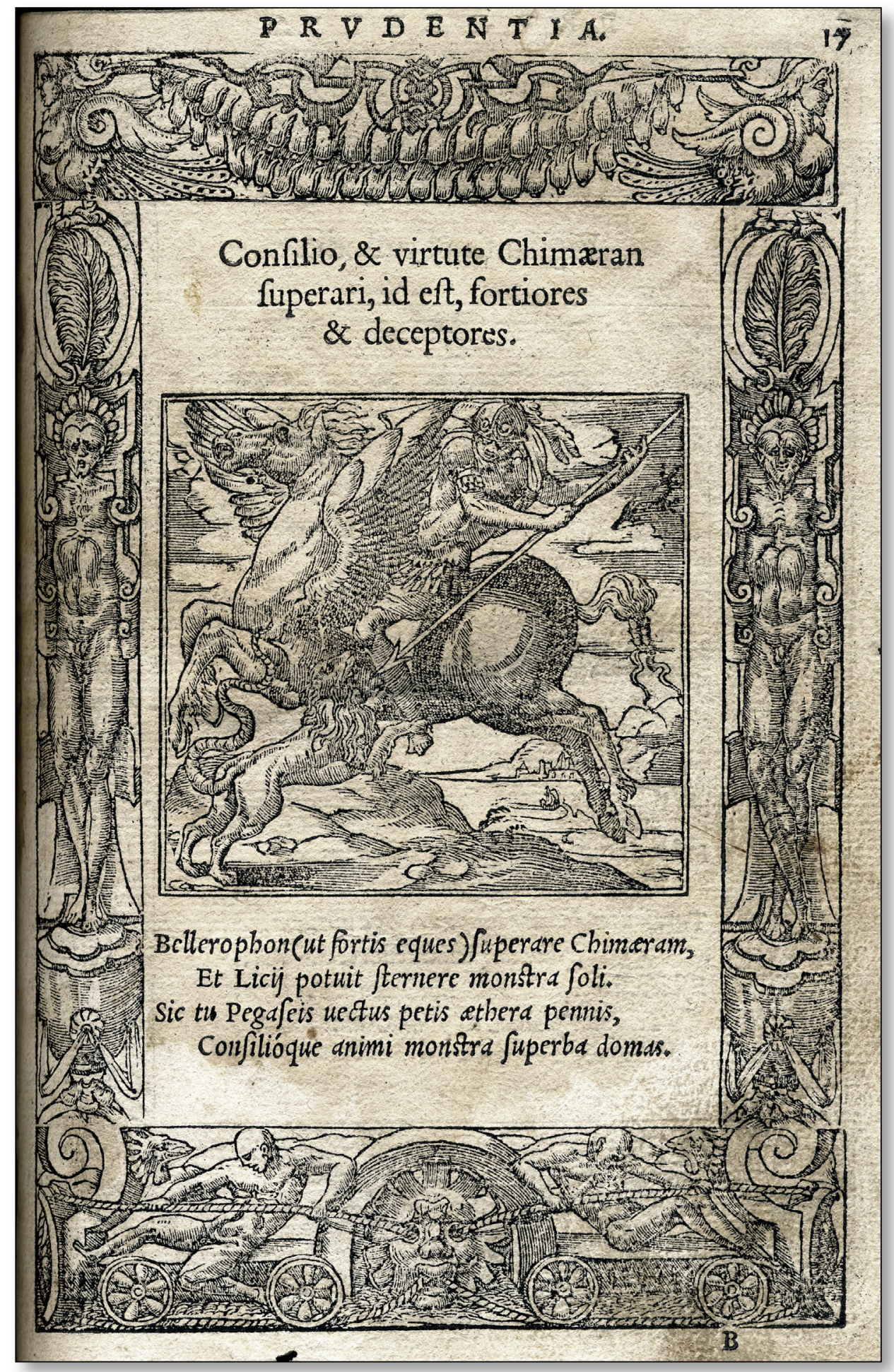

Fig. 4. La Prudencia. Emblemata Andreae Alciati Iurisconsulti clarissimi, Lyon, M. Bonhomme, 1548, p. 17. 
Este es uno de los diez emblemas que el milanés dedicó a la Prudencia. La moralidad del emblema denunciaba los vicios, que pueden ser superados con la Inteligencia que proviene de la virtud de la Prudencia del tiempo. La moralizada sentencia del salmo, junto a la cita del Evangelio de san Juan (Jn 12,25): «Qui amat animam suam, perdet eam» [fig. 2d], instruye para despertar del desengaño, ensalzando el alma como embajadora de la vida y la única que acompaña a la muerte. Pero esta la estancia terrenal debe vivirse despojada de los malos hábitos o placeres terrenales. En el centro del «mundo en T», se lee «Infern ${ }^{9}$ (Infernus) [fig. 2e]. Nos recuerda que en el Infierno se encuentran los pecadores. Una fuente indirecta que comparte una unidad de espíritu similar pudo haber sido el Infierno de la Comedia de Dante por su coincidencia de conceptos referidos a la Prudencia. ${ }^{16}$

El tiempo, como componente terrenal y negativo por su fugacidad, se transforma en positivo y divino con la infinitud. Venegas va a representar esa concepción de triunfo final en el programa iconográfico del emblema musical, a saber, la eternidad y lo divino. La música en los versos de Manrique se tornará, con sus artificios retóricos, en herramienta para el alcance de este propósito. El espíritu hermético-emblemático toma sentido cuando una cosa muestra y oculta simultáneamente otra. La forma musical responde al contrapunto imitativo a la quinta a tres voces con entradas canónicas ${ }^{17}$ para cada una de ellas. De textura contrapuntística, las melodías fluyen independientes primando las relaciones horizontales de las voces. El signo mensural es característico del Cinquecento, tempus imperfectum cum prolatio minor, transcrito en 4/4, en relación interger valor $(1: 1)^{18}$ [fig. 5]. Al llegar a la última nota de cada voz, un signo musical nos marca la repetición y nos devuelve al inicio de la voz. De tal manera, podemos interpretar los tres pentagramas de las voces dibujando con ellos tres círculos perfectos y eternos, volviéndose la música icónica. ${ }^{19}$ La rueda de la fortuna -atributo de la vanitas- se nivela con la muerte en el tiempo, por lo que aquello que está debajo pronto estará arriba. Estos signos de repetición proponen el imaginario icónico de las tres ruedas del tiempo trazadas con los pentagramas [fig. 6], las tres facultades: pasado, presente y futuro que se corresponden con el cantus (la tesitura más alta), el altus (la intermedia) y el bassus (la voz más grave, la que yace como la muerte que vendrá con el futuro). ${ }^{20}$

general representan el mal o el pecado, reacios ante el llamado admonitorio de la virtud o sometidos a ella» (Guglielmi, 2002: 24)

16. "Conceived as it was in France, the country that contributed so strongly to the Trinitarian cult, one may well wonder whether Busnois's circular canon was perhaps not inspired by one of those circular ideograms which occur in French manuscripts of the thirteenth and fourteenth centuries (see above). Another source of inspiration may have been Dante's Divine Comedy. At the end of his journey through Paradise the poet describes his vision of the Trinity as follows: 'In the profound and clear ground of the lofty light appeared to me three circles of three colours and of the same extent, and the one seemed reflected by the other as rainbow by rainbow, and the third seemed fire breathed forth equally from the one and the other' (Canto XXXIII, 115-120). In using the circle as an emblem of perfection, Dante for his part was perhaps influenced by Thomas Aquinas, who transposed this Neoplatonic theme so as to express the return of all created things to God: 'Circularity completes the movement of the soul in that it leads to God'» (Elders, 1994: 196-197).

17. "In the music of the fourteenth through the sixteenth centuries, the term canon (i.e., rule) has a much wider significance than it has in the ensuing periods and today. It means any kind of prescription that contains a clue to the correct interpretation of music which would otherwise be obscure. Tinctoris, in his Diffinitorium (ca. 1500, see CS iv, 179) defines it thus: 'Canon est regula voluntatem compositoris sub obscuritate quadam ostendens' (A canon is a rule which shows the intention of the composer in an obscure way)» (Apel, 1953: 179-180).

18. La música en notación mensural blanca del emblema ha sido transcrita a edición mensurstriche con incipit y se le ha incorporado un excipit. El código QR, adjunto a la partitura en la figura 5, muestra cómo suena el emblema. 19. "Le canon est à la fois le réceptacle d'edées, d'idéologies et de symboles, et le lieu musical où les compositeurs se font théologiens et exégètes. La sciencie musicale du contrepoint et la fascination des combinatoires infinies se conjuguent en des formes d'art total où dialoguent texte, musique et image» (Wuidar, 2008: 14).

20. "There is a clear concentration of pieces in circular notation in the first decades of the sixteenth century. They occur in different media and are all embedded in a specific iconographic programme» (Schiltz, 2017: 282).

IMAGO, NÚM. I3, 202I, 7-23 


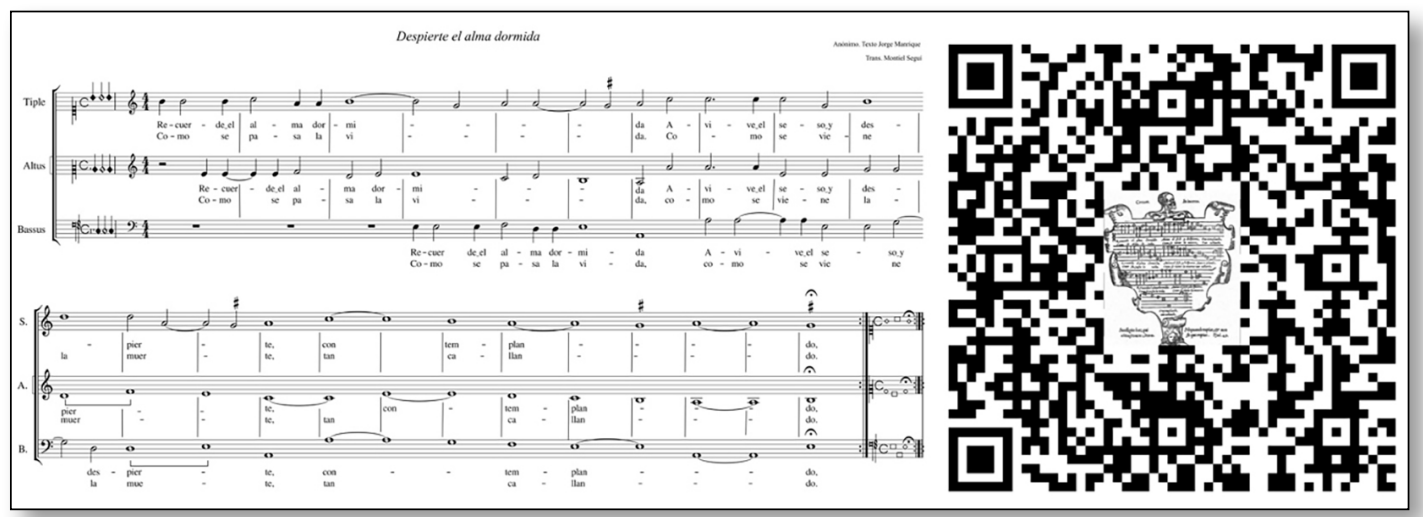

Fig. 5. Transcripción del emblema musical de la vanitas y QR. Libro de cifra nueva, Luis Venegas de Henestrosa, 1557.

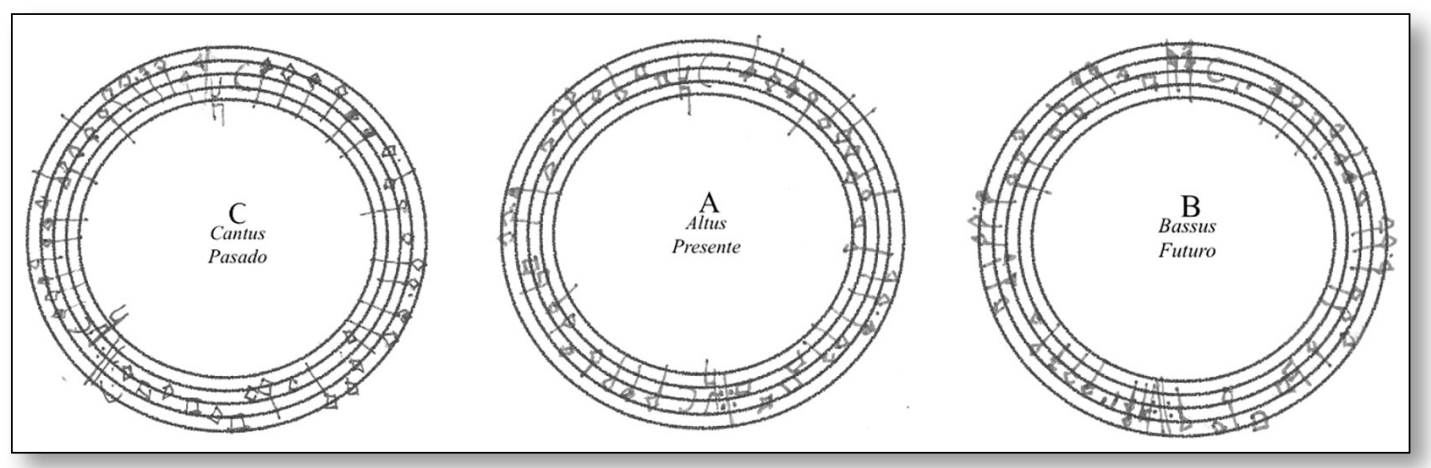

Fig. 6. Rueda del cantus-pasado, rueda del altus-presente, rueda del bassus-futuro.

Recuerdan los artificios retóricos musicales del emblema de Venegas al arte de la memoria luliano, de arraigo aristotélico, el cual proyectaba a la Trinidad mediante Dignidades divinas, pudiendo ser empleado por las tres potencias del alma de san Agustín: intellectus, el arte de encontrar la verdad; voluntas, la disciplina de la voluntad; y la memoria, con cuyo arte se recordaría la verdad. Las figuras del arte de Llull, como el de Venegas, a diferencia del arte de la memoria clásico donde los loci son estáticos, son círculos dinámicos que rotan señalados con notación alfabética, principalmente letras iniciales; en el caso de la música del emblema las voces se indican desde el inicio de la notación con las letras capitulares de las voces: C para el cantus, A para el altus, B para el bassus, etc. El movimiento concéntrico de estas ruedas giratorias son el movimiento del alma que se pronuncia en los versos de Manrique a través de estructuras trinitarias ${ }^{21}$ musicales, como ocurría con el arte de la memoria luliano.

Lo ternario constituye un elemento importante en los valores significantes del emblema, el juego de las tres dimensiones temporales, la construcción musical a tres voces junto a las ruedas giratorias temporales y, en su constitución más mínima, células motívicas

21. "Some compositions which exemplify two related contrapuntal techniques used by musicians in the fifteenth and sixteenth centuries to contribute to the rich diversity of Trinitarian representations» (Elders, 1994:185). 
compuestas de tres unidades con el signo gráfico de notación musical en función retórica. Destacan dos patrones de células rítmicas de tres notas:

1. Semimínima-mínima-semimínima es el patrón inicial de las tres voces [fig. 7a]. Tiple: compás 1; altus: dos últimos tiempos c. 1 junto a los dos primeros tiempos del c. 2; bassus en c. 4.

2. Mínima-mínima con punctus additionis o perfectionis-mínima [fig. 7b] es el patrón inicial del segundo verso. Tiple: dos últimos tiempos del c. 7 y c. 8; altus: dos últimos tiempos del c. 7 y c. 8 ; bassus: c. 8 junto al primer tiempo del c. 9 .

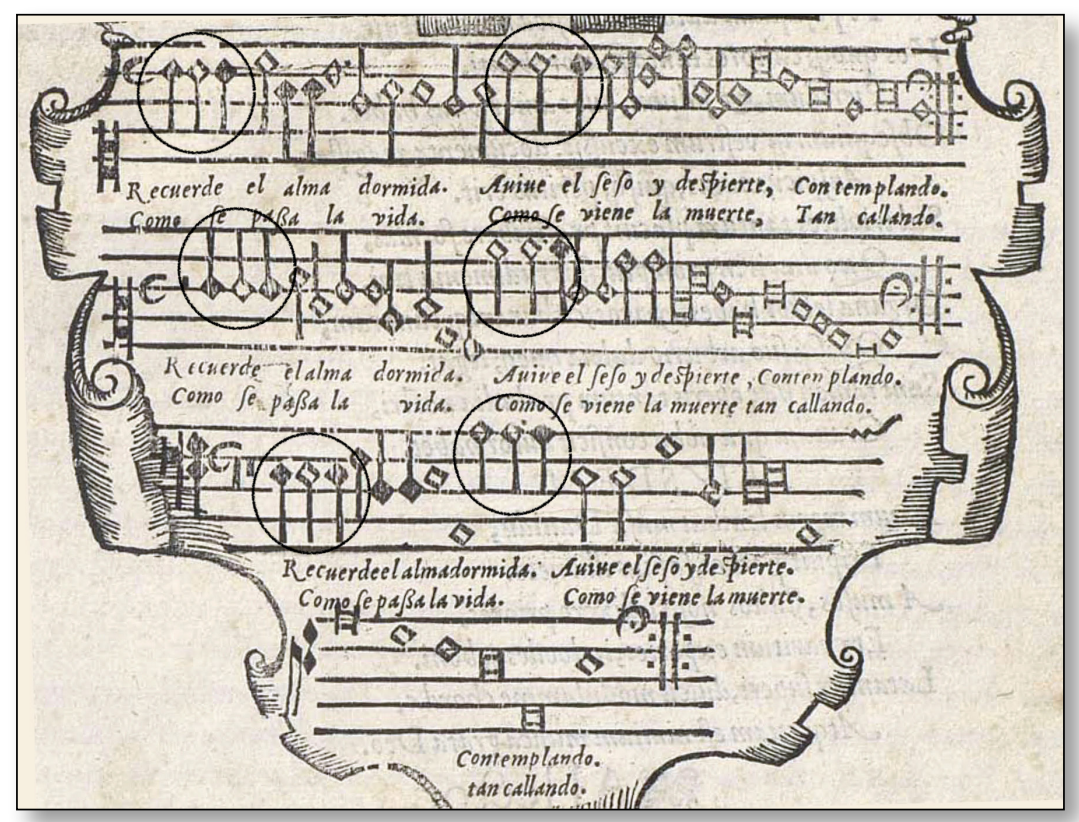

Fig. 7. Motivo inicial (a) y motivo segundo (b). Libro de cifra nueva, Luis Venegas de Henestrosa, 1557, Alcalá de Henares. Biblioteca Nacional de España, fol. ii r.

En cuanto a estas células musicales de repetición de notas, Zarlino, ${ }^{22}$ en L'Istituzioni (1558), señala:

En el canto figurado se toleran las repeticiones; y no digo ya de una sílaba o palabra, sino alguna parte de la oración, cuando el sentido es perfecto, y esto se puede hacer cuando hay notas en tanta cantidad que se pueden repetir cómodamente, si bien el repetir sea una cosa (a mi modo de ver) que no esté muy bien, a no ser que se haga para expresar principalmente palabras que encierran una grave sentencia digna de consideración (Rubio, 1974: 105).

22. Gioseffo Zarlino será uno de los teóricos renacentistas fundamentales en el pensamiento matemático-racional de la música que expondrá en sus tres tratados: Instituciones armónicas (1558), Demostraciones armónicas (1571) y Suplementos musicales (1588). Será en el siglo XVI cuando el sistema musical basado en los modos medievales -de origen griego- comience a transitar hacia la tonalidad (modo mayor y modo menor).

IMAGO, NÚM. 13, 2021, 7-23 
Los tres motivos rítmicos de las tres voces iniciales, así como los tres patrones situados en el inicio de los siguientes versos, están colocados sobre palabras claves en la significación de la fugacidad de la vida del texto de Manrique, en el pasado: «recuerde» y «avive». La segunda palabra, además, en la segunda nota -primer tiempo, sincopado, del compás 8 de las tres voces- le corresponde un punctus additionis por lo que, alargando la segunda vocal, quedaría separada dando un significado propio a "vive», resaltando el mensaje subliminal de la vanitas. Además, la palabra "vive» queda en un solo compás (c. 8), tanto en el tiple como en el altus.

Otra figura retórico-musical vinculada a la ley del tres, recae en la palabra "muerte» del texto de Manrique, que aparece representada con la notación de la música. En el compás 13 y compás 14 del cantus las tres grafías de notación musical -semibreve, mínima, semibreve- dibujan el signo de la cruz ${ }^{23}$ [fig. 8] a través de la figuración por grados conjuntos en intervalos de segunda -descendente y ascendente-, y se convierten en artificio retórico musical, ${ }^{24}$ además sobre la música ficta sol\#, como cromatismo asociado al dolor o al lamento en la cadencia.

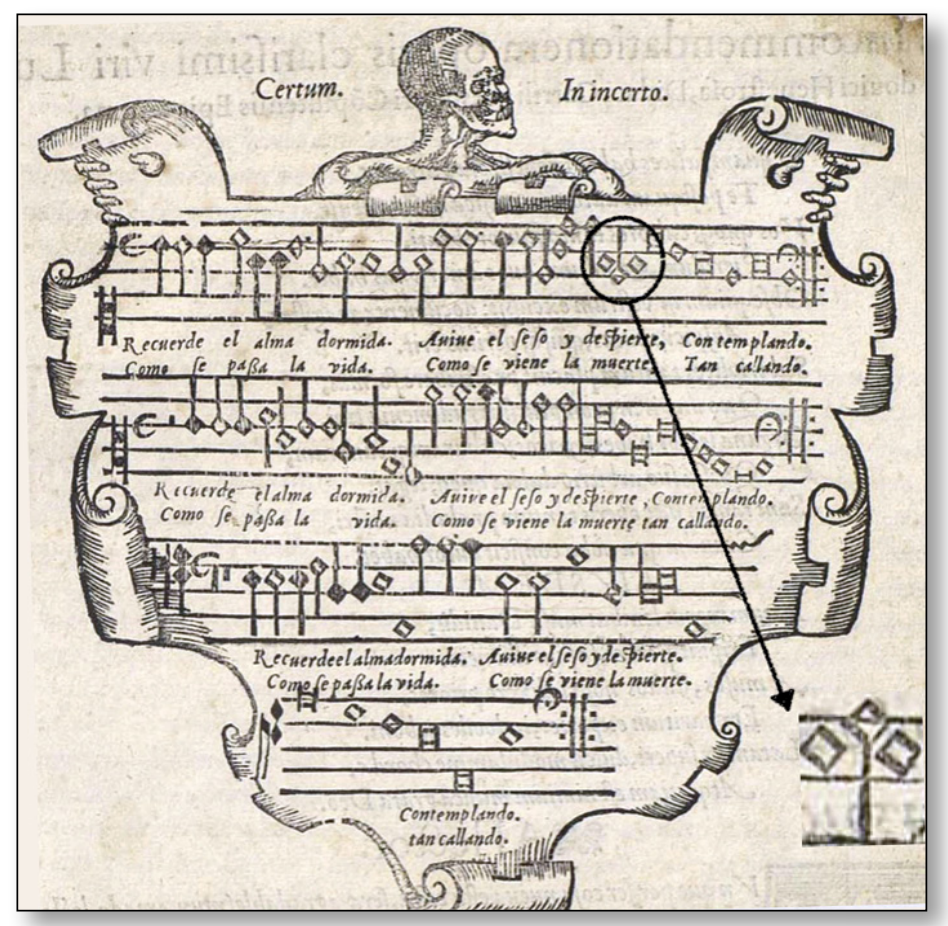

Fig. 8. Motivo de la cruz. Libro de cifra nueva, Luis Venegas de Henestrosa, 1557, Alcalá de Henares. Biblioteca Nacional de España, fol. ii r.

23. En un fragmento de la cantata $n^{\circ} 4$ de Johann Sebastian Bach (Christ lag in Todesbanden) está representado el símbolo de la cruz y las tres cruces del escenario del Gólgota. "Aquí Bach traza con gran parsimonia el perfil de la Cruz formado por cuatro notas antes de indicar a los violines que retomen su concierto. [...]. En el centro del mismo himno se encuentra una evocación de la wunderlicher Krieg, esa batalla maravillosa librada entre las fuerzas de la vida y la muerte, el viejo tiempo y el nuevo" (Eliot Gardiner, 2015: 219).

24. Esta figura retórica podría asociarse a la hypotyposis: "[...] a vivid musical representation of images found in the accompanying text. [...] The hypotyposis is given the same task in music as in rhetoric: to vividly and realistically illustrate a thought or image found in the text. As such it might even be considered the most important and common text-expressive compositional device of Baroque music, for it is musica poetica's mandate to delight and move the listener through a musical presentation of the text. Such musical word painting becomes a hallmark of Baroque music, being found in virtually every Baroque vocal 
Con todas estas singularidades, Luis Venegas de Henestrosa nos legaba un emblema musical pleno de mensajes herméticos, en el único tratado musical impreso que se conserva de su autoría, aún sabiendo que en su testamento mandó imprimir (Jambou y Reynaud, 1984), a sus albaceas, la Armonía de los tres mundos, del que nada hemos vuelto a saber.

\section{A MODO DE CONCLUSIÓN}

Tomando prestada la memoria activa del imaginario icónico del tiempo y su fugacidad, el emblema de Venegas seguía la tradición de aquel modo de ver la vida en su sentido alrededor de la muerte. Las horas caducas recordaban el advenimiento del destino terrenal, el ser humano era aleccionando sobre cómo debía vivir la vida, desengañado, despreciando todo placer o vicio mundano.

El registro de cada una de las artes representadas en la estampa era aunada por la retórica al servicio de la vanitas. Literatura, música, artes visuales y ciencia se contestaban con sus artificios retóricos articulados hacia un mismo sentido o significado. Este diseño interdisciplinar velaba el mensaje en el que giraba musicada la Prudencia del tiempo. Lo ternario, lo infinito y lo sagrado se constituían importantes en los valores significantes del emblema en correspondencia a los patrones triádicos. Venegas presentaba el juego de las tres dimensiones temporales, tres sub-lemas, un mundo dividido en tres continentes, tres voces que dibujan con sus pentagramas en el imaginario icónico las tres ruedas giratorias temporales y, en su constitución más mínima, células motívicas compuestas de tres unidades con el signo gráfico de notación musical en función retórica.

La literatura le prestó las glosas del poeta don Jorge Manrique, escritas aproximadamente un siglo antes de la publicación del Libro de cifra nueva; versículos sagrados (Jn 12,25; Sal 49,22 ) lanzaban mensajes sobre cómo preparar el alma y de advertencia del poder de Dios sobre el hombre; referencias al Infierno persuadían al creyente. Las imágenes dibujaban contornos como la anatomía moralizada del esqueleto que porta como estandarte los versos musicados del poeta, mientras su calavera hacía el gesto del prudente languidecida hacia el futuro. La alegoría de la Inteligencia contemplaba la esfera terrestre, el teatrum mundi, un «mundo en T», proveniente de la tradición medieval, suspendido del hilo de la música, en un giro inconcluso del que participan la Jerusalén terrestre y el jinete salvador que vencería los vicios terrenales. La música del emblema rotaba al tempo del mundo, la ley matemática del contrapunto a tres voces dibujaba en su órbita tres ruedas que traspasaban el imaginario sonoro hasta entrar en el reino de la iconicidad y de la memoria lulista alcanzando la plenitud. Caía el tiempo y se volvía a alzar como la rueda de la fortuna, con el pasado, el presente y el futuro, representado en sus melodías mediante las figuras retóricas mnemotécnicas de la música, evocando la metáfora que articulaba el espíritu de la vanitas.

composition. Already Burmeister laments the fact that not all composers used the device judiciously. Literally the term means an imitation or reproduction, from hypo. 'under' (re-): typosis. 'form, construct.'» (Bartel, 1997: 307). 


\section{BIBLIOGRAFÍA}

Anglés, H. [1984]. La música en la corte de Carlos V, con la transcripción del "Libro de cifra nueva para tecla, harpa y vihuela» de Luys Venegas de Henestrosa: (Alcalá de Henares, 1557), Barcelona, CSIC (Instituto Español de Musicología).

Apel, W. [1953]. The Notation of Polyphonic Music 900-1600, Cambridge, Mass., The Medieval Academy of America.

Bartel, D. [1997]. Musica Poetica. Musical-Rhetorical Figures in German Baroque Music, Lincoln, University of Nebraska Press.

Boecio [2006]. La consolación de la Filosofía, traducción de Pablo Masa, Madrid, Ediciones Perdidas.

Borja, J. de [1581]. Empresas morales, Praga, Iorge Nigrin (ed. de Rafael García Mahíques, Ajuntament de València, 1998).

Borja, J. de [1680]. Empresas morales, Bruselas, Francisco Foppens.

Cicerón [1997]. La invención retórica, traducción de Salvador Núñez, Madrid, Gredos.

Debus, A. G. [2018]. El hombre y la naturaleza en el Renacimiento, México, Fondo de Cultura Económica.

Einsenstein, E. L. [2003]. La imprenta como agente de cambio, México, Fondo de Cultura Económica.

Elders, W. [1994]. «Symbolic Scores. Studies in the Music of Renaissance», en: G. Bernhard F. Scholz y otros (eds.), Symbola et Emblemata. Studies in Renaissance and Baroque Symbolism. New York: E.J. Brill, 1-268.

Eliot Gardiner, J. [2015]. La música en el Castillo del cielo. Un retrato de Johann Sebastian Bach, traducción de Luis Gago, Barcelona, Acantilado.

García Mahíques, R. [1998]. Empresas Morales de Juan de Borja: imagen y palabra para una iconología, Valencia, Ajuntament de València.

Guglielmi, N. [2002]. El Fisiólogo. Bestiario Medieval, Madrid, Eneida.

Infantes, V. [1997]. Las danzas de la muerte. Génesis y desarrollo de un género medieval (siglos XIIIXVII), Salamanca, Ediciones Universidad de Salamanca.

Jambou, L. y Reynaud, F. [1984]. «Doble enigma en torno a la figura de Luis Venegas de Henestrosa. Su testamento", Revista de Musicología (SEdeM), 7, 2, 419-430.

López Terrada, M. J. y Jerez Moliner, F. [1994]. "Atlas anatómico de Crisóstomo Martínez como ejemplo de vanitas", Separata, Boletín del Museo e Instituto Camón Aznar, LVI, 5-34.

Lyell, J. P. R. [2012]. La ilustración del libro antiguo en España, traducción de Julián Martín Ramos, Madrid, Ollero y Ramos.

Moll, J. [1951]. «Músicos de la corte del Cardenal Juan Tavera (15231545): Luis Venegas de Henestrosa», Anuario Musical, VI, 155-178.

Montesinos, M. [2017]. «El tiempo en la visualidad de la Prudencia», en: B. Ballester y otros (eds.), Encrucijada de la palabra y la imagen simbólicas, Barcelona, José J. de Olañeta, 505-516.

Panofsky, E. [1987]. El significado en las artes visuales, Madrid, Alianza Forma.

Querol, M. [1981]. I. Madrigales españoles inéditos del siglo XVI. II. Cancionero de la Casanatense, Barcelona, CSIC (Instituto Español de Musicología).

Ripa, C. [2007]. Iconología, vol. 1, Madrid, Akal.

Rodríguez de la Flor, F. [2007]. Era melancólica. Figuras del imaginario barroco, Barcelona, José J. de Olañeta. 
Rubio, S. [1974]. La polifonía clásica, Madrid, El Escorial.

Rubio, S. [2006]. Historia de la música española 2. Desde el «ars nova» hasta 1600, Madrid, Alianza Música.

Salazar de Mendoza, P. [1603]. Chronico de el Cardenal don Juan Tavera, Toledo, Pedro Rodríguez.

Schiltz, K. [2017]. Music and Riddle Culture in the Renaissance, Cambridge, Cambridge University Press.

Sebastián, S. [1995]. Emblemática e Historia del Arte, Madrid, Cátedra.

Valverde, J. [1556]. Historia de la composición del cuerpo humano, Roma, Antonio Salamanca, Antonio Lafrery.

Venegas de Henestrosa, L. [1557]. Libro de cifra nueva para tecla, harpa y vihuela, Alcalá de Henares, Juan de Brocar.

Vives-Ferrándiz, L. [2011]. Vanitas. Retórica visual de la mirada, Madrid, Encuentro.

Wuidar, L. [2008]. Canons énigmes et hiéroglyphes musicaux dans l'Italie du 17 siècle, Bruxelles, P.I.E. Peter Lang. 
